\title{
Angiographic profile in diabetic and non-diabetic patients with coronary artery disease in the Cardiac Specialty Hospital - Cardiac Center, Erbil, I raq
}

Received: 2/ 5/ 2016

Accepted: $26 / 6 / 2016$

Mudhafar Abdulrahman Albarzani *

Abstract

Background and objective: Diabetic patients show two to three times higher risk of developing coronary artery disease than non-diabetics particularly in type 2 diabetes mellitus. This study aimed to find out the adverse effects of type 2 diabetes on coronary artery anatomy and the association of different socio-demographic characteristics with diabetic and non-diabetic patients with coronary artery disease.

Methods: An angiographic based cross-sectional study was conducted on 150 patients with coronary artery disease attending cardiac specialty hospital - cardiac center in Erbil city between May and September 2015. Seventy five patients of them were type-2 diabetes and others were non-diabetics.

Results: Significantly higher differences in age, sedentary lifestyle, and hypertension were seen among type-2 diabetics than non-diabetics. Development of critical and diffuse coronary artery lesions was significantly higher among type-2 diabetics than non-diabetics. Triple vessels disease was significantly higher among type-2 diabetic patients.

Conclusion: Type-2 diabetes significantly affects the anatomy of coronary arteries, and is associated with age, sedentary lifestyle, and hypertension. The findings are comparable to those of different studies in different countries.

Keywords: Coronary artery disease; Angiography; Type-2 diabetes.

\section{Introduction}

Cardiovascular diseases (CVDs) remain the biggest cause of deaths worldwide, ${ }^{1}$ contributing to $30 \%$ of global mortality and $10 \%$ of the global disease burden. ${ }^{2,3}$ In 2005, the worldwide percentage of mortality due to CVDs and coronary heart diseases (CHDs) was 29.3\% and $13.1 \%$ respectively. ${ }^{4,5}$ Globally, different risk factors are associated with increased incidence and mortality from CHDs, diabetes mellitus (DM) is one of these risk factors. ${ }^{1}$ Diabetes mellitus ranked the $2^{\text {nd }}$ commonest cause of worldwide non communicable diseases (NCDs) mortality next to CVDs. ${ }^{6}$ Diabetics show 2-3 times higher risk of developing coronary artery disease than non-diabetics particularly type $2 \mathrm{DM}$ were dyslipidemia is common. $^{7}$ Correlation between diabetes mellitus and coronary heart disease was established at 1870 after the work of
Seegen J, Der, who emphasized the higher incidence and mortality of coronary artery disease (CAD) among diabetics. ${ }^{6}$ Nationally, despite limitations in the mortality statistics available in Iraq, CVDs was the leading cause of death. Hospital morbidity data provided by the $\mathrm{MOH}$ indicates a $65 \%$ increase in hospital admissions due to CHDs between 1989 and $1999 .{ }^{8}$ Often in low and middle income countries there is a lack of information on the role of different risk factors in the development of CHDs. ${ }^{1}$ This study is an angiographic-based study aimed to find out the adverse effects of type 2 diabetes on coronary artery anatomy, and association of different socio-demographic characteristics with diabetic and nondiabetic patients with CAD.

\section{Methods}

A hospital based cross -sectional study

* Department of I nternal Medicine, College of Medicine, Hawler Medical University, Erbil, I raq. 
was performed on 150 patients with CAD; 75 patients of them were diabetics and others were non-diabetics. The study was conducted between May and Sep 2015 at the cardiac specialty hospital / cardiac center, Erbil, Iraq. Patients with CAD and known to have type 2 diabetes were included in group 1 , and patients with CAD proved to be non-diabetics were included in group 2. The diagnosis of diabetes mellitus was established when the fasting plasma glucose levels were higher than $126 \mathrm{mg} / \mathrm{dl}$ or the patient reported receiving hypoglycaemic treatment. ${ }^{9}$ Patients with type 1 diabetes, valvular heart disease, left ventricle hypertrophy, cardiomyopathy, and congestive heart failure were excluded from the study. All study participants are known to have CAD confirmed by the typical history of the disease, electrocardiography (ECG), and positive exercise ECG test. Coronary angiography was performed for all patients according to guidelines. Data on age, gender, family history of $C A D$ in first degree relatives, body mass index (BMI), waist circumference, lifestyle, smoking, drinking, and hypertension and the results of coronary angiography were recorded in an especially designed questionnaire. Patients with mean blood pressure level greater or equal to $140 / 90 \mathrm{mmHg}$ or those reported taking antihypertensive medications were classified as hypertensive. ${ }^{10}$ Angiographic findings were interpreted by the same intervention cardiologist. Lesions affecting $(\geq 50 \%)$ left main coronary artery lumen or $\geq 70 \%$ of other coronary vessel lumen called Critical lesion. On the other hand, a critical lesion affecting single coronary vessel called single vessel disease (SVD), if two vessels called double vessel disease (DVD), and if three vessels called triple vessels disease (TVD). Critical lesion affecting three of five segments of the left anterior descending artery (LAD) and left circumflex artery (LCX) or two of four segments of right coronary artery (RCA), it is called diffuse coronary artery disease. BMI was classified according to world health organization classification in 2012 into underweight $\left(<18.5 \mathrm{Kg} / \mathrm{m}^{2}\right)$, normal weight $\left(18.5-24 \mathrm{Kg} / \mathrm{m}^{2}\right)$ overweight $\left(25-29 \mathrm{Kg} / \mathrm{m}^{2}\right)$, and obese $\left(30+\mathrm{Kg} / \mathrm{m}^{2}\right){ }^{11}$ Statistical analysis was performed by using the statistical package for the social sciences (version 17). Chi-square test and independent $t$ test were used to calculate the significant differences between different study variables. A $P$ value of $\leq 0.05$ was considered statistically significant. The study was approved by research ethics committee of College of Medicine of Hawler Medical University. Informed written consent was obtained from each patient before being enrolled in the study.

\section{Results}

The mean age \pm SD of the study participants was $58.25 \pm 10.6$ years with a range of $27-80$ years. The mean age of diabetic patients $(59.4 \pm 9.20$ years) was significantly $(P=0.011)$ higher than that of non-diabetics (57.11 \pm 11.19 years). Around $75 \%$ diabetic patients and $53 \%$ of non-diabetics were in the $6^{\text {th }}$ and $7^{\text {th }}$ decades of age with statistical significant variations between the age groups $(P=0.019)$. The mean $\mathrm{BMl}$ and waist circumference \pm SD of the study sample were $30.19 \pm 5.11 \mathrm{Kg} / \mathrm{m}^{2}$ and 105.92 $\pm 10.97 \mathrm{~cm}$, respectively. Sedentary lifestyle was significantly $(P=0.014)$ higher among diabetic patients $(96.0 \%)$ than non-diabetics (84\%). Hypertension was also significantly $(P=0.029)$ higher among diabetic patients $(70.7 \%)$ than non-diabetics (53.3\%). Other socio-demographic variables had no significant associations (Table 1). 
Table 1: Association of diabetes with certain socio-demographic characteristics and other epidemiological variables.

\begin{tabular}{|c|c|c|c|c|c|}
\hline \multirow{2}{*}{ Variables } & \multicolumn{2}{|c|}{ Non-Diabetics } & \multicolumn{2}{|c|}{ Diabetics } & \multirow{2}{*}{$P$ value } \\
\hline & No. & $\%^{*}$ & No. & $\%^{*}$ & \\
\hline \multicolumn{6}{|c|}{ Age: (Mean age $\pm S D=58.25 \pm 10.6)$} \\
\hline$<50$ & 23 & 30.7 & 8 & 10.7 & \multirow{4}{*}{0.019} \\
\hline $50-59$ & 18 & 24.0 & 26 & 34.7 & \\
\hline $60-69$ & 22 & 29.3 & 30 & 40.0 & \\
\hline $70+$ & 12 & 16.0 & 11 & 14.7 & \\
\hline \multicolumn{6}{|l|}{ Gender } \\
\hline Male & 43 & 57.3 & 37 & 49.3 & \multirow{2}{*}{0.326} \\
\hline Female & 32 & 42.7 & 38 & 50.7 & \\
\hline \multicolumn{6}{|c|}{ BMI: (Mean BMI $\pm S D=30.19 \pm 5.11)$} \\
\hline$<18.5$ & 0 & 0.0 & 0 & 0.0 & \multirow{4}{*}{0.118} \\
\hline $18.5-24$ & 14 & 18.7 & 6 & 8.0 & \\
\hline $25-29$ & 26 & 34.7 & 34 & 45.3 & \\
\hline $30+$ & 35 & 46.7 & 35 & 46.7 & \\
\hline \multicolumn{6}{|c|}{ Waist circumference: (Mean \pm SD $=105.92 \pm 10.97)$} \\
\hline Normal & 15 & 20.0 & 11 & 14.7 & \multirow{2}{*}{0.388} \\
\hline High & 60 & 80.0 & 64 & 85.3 & \\
\hline Smoking & & 0.0 & & 0.0 & \multirow{3}{*}{0.19} \\
\hline No & 7 & 9.3 & 3 & 4.0 & \\
\hline Yes & 68 & 90.7 & 72 & 96.0 & \\
\hline \multicolumn{6}{|l|}{ Alcohol } \\
\hline No & 68 & 90.7 & 73 & 97.3 & \multirow{2}{*}{0.086} \\
\hline Yes & 7 & 9.3 & 2 & 2.7 & \\
\hline \multicolumn{6}{|l|}{ Lifestyle } \\
\hline Sedentary & 63 & 84.0 & 72 & 96.0 & \multirow{2}{*}{0.014} \\
\hline Active & 12 & 16.0 & 3 & 4.0 & \\
\hline \multicolumn{6}{|c|}{ Family history of $C A D$} \\
\hline No & 62 & 82.7 & 63 & 84.0 & \multirow{2}{*}{0.827} \\
\hline Yes & 13 & 17.3 & 12 & 16.0 & \\
\hline \multicolumn{6}{|l|}{ Hypertension } \\
\hline No & 35 & 46.7 & 22 & 29.3 & \multirow{2}{*}{0.029} \\
\hline Yes & 40 & 53.3 & 53 & 70.7 & \\
\hline Total & 75 & 100.0 & 75 & 100.0 & \\
\hline
\end{tabular}


Triple vessel involvement was significantly $(P=0.012)$ higher among diabetic patients $(60.0 \%)$, while single and double vessel involvement was more frequent among non -diabetic than diabetic patients $(57.3 \%$ and $34.6 \%$, respectively). Details are shown in Table 2. Unlike left main coronary artery, the proportion of critical lesions in major coronary arteries (LAD, LCX, and RCA) was higher than that of non-critical lesions in both diabetics and non-diabetics. However, only left circumflex artery demonstrated a significant $(P=0.01)$ critical lesions among diabetics than nondiabetics ( $42.7 \%$ and $26.7 \%$, respectively). Details are shown in Table 3.

Table 2: Number of coronary arteries involved among diabetic and non-diabetic patients.

\begin{tabular}{lccccc}
\hline \multirow{2}{*}{ No. of vessels } & \multicolumn{2}{c}{ Non-Diabetics } & \multicolumn{2}{c}{ Diabetics } & $P$ value \\
\hline No. & No. & $\%^{*}$ & No. & $\%^{*}$ & 5.3 \\
Single & 7 & 9.3 & 4 & 13.3 & 0.012 \\
Double & 19 & 25.3 & 10 & 21.3 & 60.0 \\
Triple & 24 & 32.0 & 16 & 100.0 \\
Total & 25 & 33.3 & 45 & 75 & \\
\hline
\end{tabular}

* Column percent.

Table 3: Types of coronary arteries involved among diabetic and non-diabetic patients.

\begin{tabular}{|c|c|c|c|c|c|}
\hline \multirow{2}{*}{ Coronary artery involved } & \multicolumn{2}{|c|}{ Non-Diabetics } & \multicolumn{2}{|c|}{ Diabetics } & \multirow{2}{*}{$P$ value } \\
\hline & No. & $\% *$ & No. & $\% *$ & \\
\hline \multicolumn{6}{|l|}{ Left main stem (LMS) } \\
\hline Normal & 67 & 89.3 & 67 & 89.3 & \\
\hline Non-critical & 6 & 8.0 & 8 & 10.7 & 0.319 \\
\hline Critical & 2 & 2.7 & 0 & 0.0 & \\
\hline \multicolumn{6}{|c|}{ Left anterior descending (LAD) } \\
\hline Normal & 16 & 21.3 & 8 & 10.7 & \\
\hline Non-critical & 17 & 22.7 & 17 & 22.7 & 0.186 \\
\hline Critical & 42 & 56.0 & 50 & 66.7 & \\
\hline \multicolumn{6}{|l|}{ Left circumflex (LCX) } \\
\hline Normal & 39 & 52.0 & 21 & 28.0 & \\
\hline Non-critical & 16 & 21.3 & 22 & 29.3 & 0.01 \\
\hline Critical & 20 & 26.7 & 32 & 42.7 & \\
\hline \multicolumn{6}{|l|}{ Right coronary artery (RCA) } \\
\hline Normal & 30 & 40.0 & 20 & 26.7 & \\
\hline Non-critical & 11 & 14.7 & 18 & 24.0 & 0.148 \\
\hline Critical & 34 & 45.3 & 37 & 49.3 & \\
\hline Total & 75 & 100.0 & 75 & 100.0 & \\
\hline
\end{tabular}


The proportion of non-diffuse critical coronary artery lesions was significantly $(P<0.001)$ higher among non-diabetics $(52.0 \%)$ than diabetics $(26.7 \%)$. On the other hand, diffuse critical lesions were significantly higher in diabetics $(56.0 \%)$ than non-diabetics $(16.0 \%)$. These results are demonstrated in Table 4.

\section{Discussion}

This study revealed that diabetics had a significantly higher mean age than nondiabetics. This finding is similar to that reported in Davangere-India in $2014,{ }^{7}$ Brazil between 1993 and 2001, ${ }^{12}$ GazaPalestine between 2010 and $2013{ }^{13}$ Albania between 2012 and 2014, ${ }^{14}$ and Bangladesh in 2009. ${ }^{15}$ However, other studies carried out in Nablus-Palestine in $2009,^{16}$ Milan-Italy between 2007 and 2008, ${ }^{17}$ Nepal between 2011 and 2013, ${ }^{18}$ and Baghdad in $2009^{19}$ revealed no significant age variations. The finding that sedentary lifestyle was significantly higher among diabetic patients than non-diabetics is similar to that of Nablus-Palestine ${ }^{16}$ study. However, studies in Brazil, ${ }^{12}$ and India $^{20}$ revealed no significant association. Hypertension was significantly associated with diabetes. This finding agrees with those reported by studies in Bangladesh in $2009,{ }^{15}$ and Germany in 2010. ${ }^{21}$ However, other studies in Brazil, ${ }^{12}$ Netherland between 2011 and 2013, ${ }^{22}$ and Baghdad between 2008 and $2009^{23}$ revealed no significant association with hypertension.
The insignificant association with smoking revealed by this study is similar to that reported in Milan-Italy, ${ }^{17}$ Germany, ${ }^{21}$ and Netherland. ${ }^{22}$ However, other studies in Bangladesh, ${ }^{15}$ Nablus-Palestine, ${ }^{16}$ and Baghdad $^{23}$ reported no association. Similarly, the insignificant association with $\mathrm{BMI}$ in this study is comparable to that reported in Gaza-Palestine ${ }^{13}$ India, ${ }^{20}$ and Finland, ${ }^{24}$ while studies in NablusPalestine $^{16}$ and Pisa-Italy ${ }^{25}$ revealed a significant association. A higher proportion of triple coronary arteries involvement among diabetic patients revealed by this study is similar to that reported in Brazil, $^{12}$ India, ${ }^{20}$ Baghdad between 2008 and 2009, ${ }^{23}$ and Pakistan. ${ }^{26}$ On the other hand, studies in Albania, ${ }^{14}$ and Milan-Italy, ${ }^{17}$ revealed no significant risk. The significant association of critical lesions in left circumflex artery among diabetic patients demonstrated in this study is similar to that reported by studies in Milan-Italy, ${ }^{17}$ Baghdad in $2009,{ }^{19}$ and Netherland. ${ }^{22}$ However, other studies in Davangere-India, ${ }^{7}$ and Bangladesh $^{15}$ revealed no significant association. On the other hand, the significant association of diffuse coronary artery lesions with diabetes demonstrated in this study is similar to that reported in Brazil, ${ }^{12}$ France, ${ }^{27}$ and Bangladesh. ${ }^{28}$ However, another study in Frence ${ }^{29}$ revealed no statistical differences for diffuse coronary artery lesions between diabetics and nondiabetics.

Table 4: Nature of coronary artery lesions among diabetic and non-diabetic patients.

\begin{tabular}{|c|c|c|c|c|c|}
\hline \multirow{2}{*}{ Nature of coronary lesion } & \multicolumn{2}{|c|}{ Non-Diabetics } & \multicolumn{2}{|c|}{ Diabetics } & \multirow{2}{*}{$P$ value } \\
\hline & No. & $\% *$ & No. & $\% *$ & \\
\hline Normal & 7 & 9.3 & 4 & 5.3 & \multirow{5}{*}{$<0.001$} \\
\hline Non-critical & 17 & 22.7 & 9 & 12.0 & \\
\hline Critical non-diffuse & 39 & 52.0 & 20 & 26.7 & \\
\hline Critical diffuse & 12 & 16.0 & 42 & 56.0 & \\
\hline Total & 75 & 100.0 & 75 & 100.0 & \\
\hline
\end{tabular}




\section{Conclusion}

Type-2 diabetes significantly affects the anatomy of coronary arteries and is associated with age, sedentary lifestyle, and hypertension. A higher proportion of triple coronary arteries disease, critical lesions in the left circumflex artery and diffuse coronary artery lesions were demonstrated in diabetic patients in this study; findings that are comparable to those of different studies in other countries.

\section{Conflicts of interest}

The author reports no conflicts of interest.

\section{References}

1. Mendis S, Puska P, Norrving B. Global atlas on cardiovascular disease prevention and control.Geneva: WHO; 2011. Available at: http://www.who.int/cardiovascular_diseases/ publications/atlas cvd/en/

2. WHO. Reducing risks, promoting healthy life. WHO Report. Geneva: WHO; 2002. Available at: http://www.who.int/whr/2002/en/

3. WHO. World health statistics 2008. Geneva: WHO; 2008. Available at: http://www.who.int/ whosis/whostat/2008/en/

4. WHO. Prevention of cardiovascular disease: Guidelines for assessment and management of total cardiovascular risk. Geneva: WHO; 2007. Available at: http://www.who.int/ cardiovascular diseases/guidelines/ PocketGL.ENGLISH.AFR-D-E.rev1.pdf

5. WHO. Preventing chronic diseases-A vital investment. Geneva: WHO; 2005. Available at: http://apps.who.int/iris/ bitstream/10665/43314/1/9241563001 eng.pdf

6. Nathan DM, Meigs J, Singer De. The epidemiology of cardiovascular disease in type-2 diabetes mellitus: How sweat it is.... or is it? Lancet 1997; 350 (S1): S14-8.

7. Srinidhi SH, Mallesh P, Yeli SM, Veeranna MG, GiriPunja M. Comparitive angiographic profile in diabetic and non-diabetic patients with acute coronary syndrome. Journal of Clinical and Diagnostic Research 2014; 8(9):MC07-10.

8. Alwan A. Health in Iraq: the current situation, our vision for the future and areas of work. $2^{\text {nd }}$ ed. Baghdad; $\mathrm{MOH} ; 2004$ [cited 2016 Apr 23]. Available at: http://www.who.int/hac/crises/irq/background/ Iraq_Health_in_Iraq_second_edition.pdf

9. Larsan $H$, Berglund $G$, LingardE $F$, Ahren $B$. Comparision of ADA and WHO criteria for diagnosis of diabetes and glucose intolerance. Diabetologia1998; 41:1124-5.

10. Moser M. WHO-International Society of Hypertension Guidelines for the Management of
Hypertension-Do these differ from the U.S. recommendations? Which guidelines should the practicing physician follow?.J Clin Hypertens (Greenwich). 1999; 1(1):48-54.

11. WHO. Global database on body mass index. Geneva: WHO; 2012. Available at: http://apps.who.int/bmi/index.jsp? introPage=intro $3 . \mathrm{html}$

12. De Sousa JMA, Herrman JLV, Teodoro $M$, Diogo S, Terceiro BB, De Paola AAV, et al. Comparison of coronary angiography findings in diabetic and non-diabetic women with non ST segment elevation acute coronary syndrome. Arquivos Brasleiros de Cardiologia 2006; 85:2.

13. Jamee A, Abed $Y$, Ramadan M, El-Rabia K, Nasser G, Hijazi M. Impact of diabetes mellitus on coronary artery disease in women attending coronary angiography in Gaza-Palestine: An observational study. Cardiology and Angiology 2015; 4(1):10-8.

14. Zera $E$, Xinxo S, Lezha M. Comparison of in hospital outcome of acute myocardial infarction in patients with vs without diabetis mellitus in Durres population. Cardiology and Angiology 2015; 3(3):130-6.

15. Parvin T, Sirajulhaque K, Abu Siddiqi MD, Habib S, Rahman M, Rahman $\mathrm{MH}$, et al. Angiographic severity of coronary artery disease in diabetic and non-diabetic patients in a tertiary care center. University Heart Journal 2014;10 (1): 13-7.

16. Mohammad HN. Cardiovascular diseases and risk factors among diabetic patients in Nablus district, West bank, Palestine: Case-control study. M.Sc thesis. An-Najah National University. Palestine; 2014. Available at: https://scholar.najah.edu/content/cardiovasculardiseases-and-risk-factors-among-diabeticpatients-nablus-district-west-bank

17. Andreini D, Pontone G, Bartorelli A, Agostoni P, Mushtaq S, Antonioli L, et al. Comparison of the diagnostic performance of 64-slice computed tomography coronary angiography in diabetic and non diabetic patients with suspected coronary artery disease. Cardiovasc Diabetol 2010; 9:80.

18. Dubey L, Guruprasad S, Subramanyam G. Relationship between type 2 diabetes mellitus and coronary artery lesion characteristics: a single center study. Nepalese Heart Journal 2013; 10(1):20-2.

19. Kadhim AR, Strak SK, Hazaa MA. Coronary angiographic findings in diabetics patients versus non-diabetics with coronary heart disease. Al-Kindy Col Med J 2013;9(1): 23-30.

20. Mahalle N, Garg MK, Naik SS, Kulkarni MV. Association of metabolic syndrome with severity of coronary artery disease. IJEM 2014; 18(5):708-14. 
21. Hadamitzky M, Hein F, Meyer $T$, Bischoff $B$, Martinoff S, Schomig A, et al. Prognostic value of coronary computed tomographic angiography in diabetic patients without known coronary artery disease. Diabetes Care 2010; 33(6):1358-63.

22. Krul MM, Bogaard $\mathrm{K}$, Knol RJ, Rossum AC, Knaapen $\mathrm{P}$, Cornel $\mathrm{JH}$, et al. Coronary artery disease in patients with a typical chest pain with and without diabetes mellitus assessed with coronary CT angiography. BMJ Open Diabetes Research and Care 2014;2:1-9.

23. Hussein MF. Clinical and angiographic findings in diabetic versus non-diabetic Iraqi patients with ischemic heart disease (A single center experience). The Iraqi Postgraduate Medical Journal 2011;10(3): 339-46.

24. Rezende PC, Rahmi RM, Uchido AH, Costa LM, Scudeler TL, Garzillo CL, et al. Type 2 diabetes mellitus and myocardial ischemic preconditioning in symptomatic coronary artery disease patients. Cardiovasc Diabetol 2015;14:66.

25. Natalia A, Vichi S, Landi P, Severi S, L’Abbate A, Ferrannini E. Coronary atherosclerosis in type 2 diabetes: angiographic findings and clinical outcome. Diabetologia 2000;43 (5):632-41.

26. Ahmed J, Rathi N, Alam MT, Baloch Z, Munaf A, Maheshwari B, et al. Acute myocardial infarction; a comparative study to assess the angiographic changes in diabetic and non diabetic patients. Professional Med J 2015; 22(8):996-1000.

27. Ledru F, Ducimetiere P, Battaglia S, Courbon D, Beverelli F, Guize L, et al. New diagnostic criteria for diabetes and coronary artery disease: insight from angiographic study. J Am Coll Cardiol 2001; 37(6):1543-50.

28. Afsar MN, Ahmed K, Rahman S. A comparative study of coronary angiographic (CAG) findings between diabetic and non-diabetic patients. Medicine Today 2014;26(2): 95-9.

29. Cariou B, Bonnevie L, Mayaudon H, Dupuy O, Ceccaldi B, Bauduceau B. Angiographic characteristics of coronary artery disease in diabetic patients compared with matched non-diabetic subjects. Diabetes Nutr Metab. 2000;13(3):134-41. 